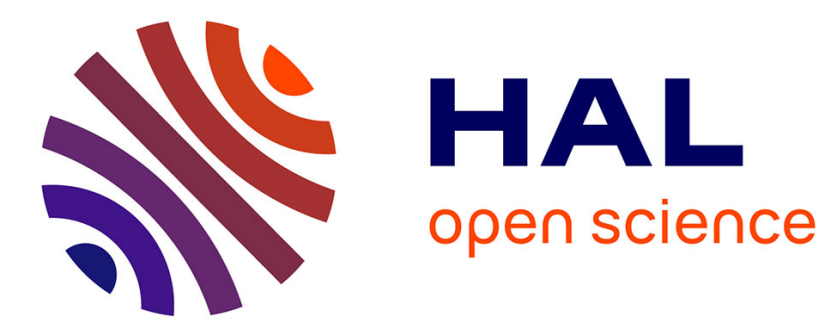

\title{
Hybrid coatings with collagen and chitosan for improved bioactivity of $\mathrm{Mg}$ alloys
}

\author{
Laura C. Córdoba, Andreia Marques, Maryna Taryba, Thibaud Coradin, \\ Fatima Montemor
}

\section{- To cite this version: \\ Laura C. Córdoba, Andreia Marques, Maryna Taryba, Thibaud Coradin, Fatima Montemor. Hybrid coatings with collagen and chitosan for improved bioactivity of $\mathrm{Mg}$ alloys. Surface and Coatings Technology, 2018, 341, pp.103-116. 10.1016/j.surfcoat.2017.08.062 . hal-01585205}

\section{HAL Id: hal-01585205 https://hal.sorbonne-universite.fr/hal-01585205}

Submitted on 12 Sep 2017

HAL is a multi-disciplinary open access archive for the deposit and dissemination of scientific research documents, whether they are published or not. The documents may come from teaching and research institutions in France or abroad, or from public or private research centers.
L'archive ouverte pluridisciplinaire HAL, est destinée au dépôt et à la diffusion de documents scientifiques de niveau recherche, publiés ou non, émanant des établissements d'enseignement et de recherche français ou étrangers, des laboratoires publics ou privés. 


\section{Hybrid coatings with collagen and chitosan for improved bioactivity of Mg alloys}

Laura C. Córdoba, ${ }^{\mathrm{a}, \mathrm{b}, *}$, Andreia Marques ${ }^{\mathrm{a}, \mathrm{c}}$, Maryna Taryba ${ }^{\mathrm{a}}$, Thibaud Coradin ${ }^{\mathrm{b}}$,Fatima Montemor ${ }^{\mathrm{a}}$, ${ }^{a} C Q E$, DEQ, Instituto Superior Técnico, Universidade de Lisboa, Av. Rovisco Pais, 1049-001 Lisboa, Portugal ${ }^{b}$ Sorbonne Universités, UPMC Univ Paris 06, CNRS, Collège de France, Laboratoire de Chimie de la Matière Condensée de Paris, 11 place Marcelin Berthelot, 75005 Paris, France ${ }^{c}$ ISQ-Instituto de Soldadura e Qualidade, Tagus Park, 2740-120 Porto Salvo, Portugal

*Corresponding author: Laura C. Córdoba

Postal Adress: Instituto Superior Técnico, Lab. de tecnologia electroquímica, Pavilhão de Minas, Piso 4, Av. Rovisco Pais, 1049-001 Lisboa, Portugal.

Fax: +351218417991

E-mail adresses: pitela@gmail.com (Laura C.Córdoba), aimarques@isq.pt_(Andreia Marques), maryna.taryba@tecnico.ulisboa.pt (Maryna Taryba), thibaud.coradin@upmc.fr (Thibaud Coradin), mfmontemor@tecnico.ulisboa.pt (Fatima Montemor). 


\begin{abstract}
Bi-layered functional coatings were developed to modify the surface of AZ31 and ZE41 Mg alloys intended as biodegradable implant materials for bone repair applications. An inner silane- $\mathrm{TiO}_{2}$ coating was designed to slow down the degradation rate of $\mathrm{Mg}$ alloys while a topmost biopolymer layer, composed of collagen or chitosan, was intended to improve bioactivity and biocompatibility of the alloys. Scanning vibrating electrode technique (SVET) and scanning ion-selective technique (SIET) were used to study the localized corrosion phenomena and localized $\mathrm{pH}$ evolution of silane- $\mathrm{TiO}_{2}$ coated $\mathrm{Mg}$ alloys. Electrochemical impedance spectroscopy (EIS) evaluation of bi-layered alloys in simulated body fluid (SBF) showed that the presence of the biopolymers promotes formation of carbonated compounds within the corrosion products. Localized electrochemical impedance spectroscopy (LEIS) results revealed that the top-most biopolymer layers do not have a detrimental effect on the barrier properties of the silane- $\mathrm{TiO}_{2}$ coating. Indeed, formation of gas pockets evidenced that collagen and chitosan layers trap evolved $\mathrm{H}_{2}$ avoiding its release into the solution at early stages of immersion. The here reported results contribute to elucidate the corrosion mechanisms of AZ31 and ZE41 Mg alloys on the long term in a biological context and provide promising insights into their control via a multilayered coatings.
\end{abstract}

Keywords: Mg alloy; sol-gel coating; collagen; chitosan; bioactivity; functionalization. 


\section{Introduction}

Since the beginning of the year 2000, Mg alloys have gained popularity as new class of materials to fabricate biodegradable metallic implants. Biodegradable metallic implants are thought to provide temporary support on healing processes or diseased tissues and progressively degrade thereafter [1]. Among other types of biodegradable metals, such as zinc and iron-based alloys, $\mathrm{Mg}$ alloys have been considered as remarkable due to their good bioactivity [2], mechanical properties similar to that of human bone [3] and because in its elemental form $\mathrm{Mg}$ is a necessary co-factor used by 700-800 enzyme systems that participate in vital metabolic processes in the human body [4]. Despite the evident benefits of using $\mathrm{Mg}$ alloys for bone repair applications, their particular corrosion behavior in aqueous environments, especially when compared to Ti alloys [5], has significantly hampered their successful application as biodegradable implants in clinical therapy.

Corrosion response of $\mathrm{Mg}$ alloys depends upon several factors such as the composition of the exposure environment $[6,7]$, the presence of impurity elements $[8,9]$ and the alloy composition $[2,10]$ among others. Among several methods to slow down the intrinsic fast degradation of $\mathrm{Mg}$ alloys, conversion films and surface coatings are considered as most effective to improve corrosion resistance and biocompatibility of $\mathrm{Mg}$ alloys. Nevertheless, a single surface treatment might not meet the requirements of $\mathrm{Mg}$ alloys in some working conditions simulating the human body [11]. Therefore, surface modifications combining two or more kinds of surface treatments to form either multi-layered [11] or hybrid coatings have been developed rapidly during last few years. Literature unveils various kinds of materials that can be successfully deposited onto the substrates by combining inorganic and organic substances. Collagen and chitosan polymers are examples of materials originating from tissue-based and plant-based sources that provide further functionalities to surface coatings, 
such as enhanced biocompatibility and cell delivery $[12,13]$. Some investigations have reported that collagen coatings deposited onto $\mathrm{Mg}-\mathrm{Zr}$ alloys enhanced surface energy and hydrophobicity of these materials [14]. Furthermore, hydroxyapatite/collagen composites coatings have shown to improve corrosion resistance of an AZ31 Mg alloy in 1.5-fold Hank's solution as well as suppressing the sharp $\mathrm{pH}$ rising and the extensive $\mathrm{Mg}^{2+}$ release from the substrate [15]. In the same way, chitosan has been used in combination with other materials, such as $\mathrm{TiO}_{2}$ and hydroxyapatite [16], as coating on metals to improve surface biocompatibility/bioactivity. In vitro corrosion tests in artificial sweat solution showed that chitosan coatings improved corrosion resistance of commercially-pure $\mathrm{Mg}, \mathrm{AZ} 91$ and AZ31 alloys [17].

Here, we proposed hybrid bi-layered coatings of silane- $\mathrm{TiO}_{2}$ and collagen or chitosan biopolymers added as top-most layers to improve corrosion resistance and biocompatibility of AZ31 and ZE41 Mg alloys. In vitro electrochemical tests allowed characterizing the barrier properties of the bi-layered coatings in simulated body fluid. The influence of the biopolymers on the silane- $\mathrm{TiO}_{2}$ coating barrier properties was elucidated by localized electrochemical techniques. 


\section{Experimental procedures}

\subsection{Materials, sol-gel deposition and thermal conditioning}

Rods of AZ31 and ZE41 Mg alloys supplied by Magnesium Elektron Company were cut into discs and sequentially grinded up to $1000 \mathrm{SiC}$ grit paper. Grinded discs were chemically treated with $12 \%$ hydrofluoric acid (HF) to promote the formation of a $\mathrm{MgF}_{2}$ layer for improved corrosion resistance of the alloys [18] and improved coating adhesion to the substrates [19]. Next, 12\%HF-treated discs were dipped into a mixed alkolsol solution of titanium (IV) iso-propoxide ( $\geq 97 \%$ TIP, Aldrich) and (3-glycidoxypropyl)-trimethoxysilane ( $\geq 98 \%$ GPTMS, Aldrich) of volume ratio 1:1.5, respectively. Finally, dip-coated samples were dried at $120^{\circ} \mathrm{C}$ for 90 minutes in air. Further details of the alloys chemical composition, synthesis and deposition of the silane- $\mathrm{TiO}_{2}$ are reported in [20]. Coupons chemically treated with $12 \% \mathrm{HF}$ are referred as pre-treated henceforth. Sol-gel coated coupons of the alloys are denoted as AZ31_S and ZE41_S (S: sol-gel).

\subsection{Bi-layered coatings deposition}

Top layers of collagen or chitosan biopolymers were deposited onto AZ31_S and ZE41_S. Diluted $0.005 \mathrm{M}$ acetic acid solutions at a concentration of $3 \mathrm{mg} \cdot \mathrm{mL}^{-1}$ in collagen (extracted and purified from rat tail tendon [21]) or chitosan (from shrimp shells $\geq 75 \%$ deacetylated,Sigma) were prepared. AZ31_S and ZE41_S coupons were manually dipped into collagen or chitosan acid solutions twice for 10 seconds each. Drying for 15 minutes at room temperature between dips was allowed. Two bi-layered coatings were produced for each alloy: (i) silane- $\mathrm{TiO}_{2}+$ collagen and (ii) silane- $\mathrm{TiO}_{2}+$ chitosan and denoted as AZ31_SC, ZE41_SC (SC: sol-gel+collagen), AZ31_SK and ZE41_SK (SK: sol-gel+chitosan).

\subsection{Morphological characterization of as-deposited coatings}


The morphological characterization of pre-treated, silane- $\mathrm{TiO}_{2}$ coated and bi-layered AZ31 and ZE41 alloys was performed by scanning electron microscopy (FEG-SEM, JEOLJSM7001 F) and atomic force microscopy (AFM, Nanosurf Easyscan 2). Morphological results of pre-treated and silane- $\mathrm{TiO}_{2}$ coated alloys were discussed in detail in [20]. To characterize cross-sections of the bi-layered coatings, samples were embedded into an epoxy resin (Buehler) mould at room temperature and grinded up to $2500 \mathrm{SiC}$ grit paper in ethanol.

\subsection{In vitro corrosion characterization by electrochemical techniques}

\subsubsection{Localized electrochemical impedance spectroscopy (LEIS)}

Localized electrochemical impedance spectroscopy measurements were carried out using a Solartron 1286 electrochemical interface and a Solartron 1250 frequency response analyzer coupled with a Uniscan M370 workstation. LEIS equipment uses a five-electrode configuration consisting of a conventional three-electrode cell: (i) saturated calomel electrode (SCE) as reference, (ii) platinum mesh as counter electrode and (iii) sample as working electrode; and the LEIS probe (Pt bi-electrode) to measure the local potential gradient in solution above the sample surface. For LEIS measurements a special sample setup was made. The samples had two different regions with different surface preparations: (i) sol-gel coated and (ii) bi-layered with either collagen or chitosan, prepared following the procedures described in sections 2.1 and 2.2. The final sample setup is represented in Fig. 1. For LEIS mapping the probe was stepped across a defined area centered at the boundary of the two different surface conditions, as represented in Fig. 1a. The dimension of the scanned area was $14 \mathrm{~mm}^{2}$. All recorded maps were taken with a constant excitation frequency of $10 \mathrm{~Hz}$ and are presented in terms of admittance modulus, in order to follow the slowest corrosion processes occurring at the metal surface. Since diluted solutions aid to optimize lateral resolution, LEIS 
experiments were performed at room temperature in $25 \%$ SBF solution with a conductivity of $3.5 \mathrm{mS}$.

\subsubsection{Scanning vibrating electrode technique (SVET) and scanning ion-selective technique} $\underline{(S I E T)}$

To evaluate localized corrosion and $\mathrm{pH}$ gradients on the silane- $\mathrm{TiO}_{2}$ coated alloys scanning vibrating electrode technique (SVET) and scanning ion-selective technique (SIET) were used, respectively. An artificial defect $500 \mu \mathrm{m}$-length was created on AZ31_S and ZE41_S samples using a microindenter Ernst Leitz Wetzlar with a load of 500 gr. The defect was intended to mimic a local delaminated area that emerges in a coated sample at advanced stages of immersion leading to changes in electrochemical potential, current density and acid-base equilibrium reactions around that area [22]. The artificial defect was in the center of the scanned area of $0.9 \mathrm{~mm} \times 0.6 \mathrm{~mm}$ approximately. The rest of the sample surface was isolated by covering with bee wax. Local current density and $\mathrm{pH}$ were mapped at $31 \times 31$ grid generating 961 data points. Periodical measurements were taken during exposure to SBF at room temperature during 24 hours.

For SVET measurements an insulated Pt-Ir probe (Microprobe Inc.) with a spherical layer of platinum black deposited on the tip probe was used as vibrating electrode. The probe was positioned $100 \pm 3 \mu \mathrm{m}$ above the sample. The vibration amplitude in vertical $(z)$ and horizontal $(x)$ planes was $32 \mu \mathrm{m}$ peak to peak. The probe diameter was $18 \mu \mathrm{m}$ and the vibration frequencies in $z$ and $x$ planes were $124 \mathrm{~Hz}$ and $325 \mathrm{~Hz}$, respectively. Only the data from the vertical plane vibration $(z)$ were taken into consideration.

For SIET measurements an $\mathrm{Ag} / \mathrm{AgCl} / \mathrm{SBF} \mathrm{pH}$-selective glass-capillary microelectrode was used as the external reference electrode. Micropipettes of silanized glass were backfilled with the inner filling solution and tip-filled with an $\mathrm{H}^{+}$-selective ionophore-based membrane. 
The glass-capillary tip diameter was $1.8 \pm 0.2 \mu \mathrm{m}$. Calibration of the $\mathrm{H}^{+}$-selective microelectrode using commercially available $\mathrm{pH}$ buffers (Fluka) within the $\mathrm{pH} 2-10$ range was made before and after measurements to correlate the recorded data with the Nernst equation [23] in order to consider possible potential drifts. The $\mathrm{H}^{+}$local activity was detected $30 \pm 3 \mu \mathrm{m}$ above the sample surface.

SVET and SIET techniques were performed separately on different samples with identical preparation. The equipment used in this study was a commercial device from Applicable Electronics ${ }^{\mathrm{TM}}$ controlled by ASET software (Science Wares ${ }^{\mathrm{TM}}$ ). All measurements were performed using a Faraday cage to avoid electromagnetic interferences. Sol-gel coated AZ31_S and ZE41_S samples were tested only.

Morphology and chemical composition of all surface conditions after EIS, SVET and SIET experiments were analyzed by SEM equipped with an energy dispersive spectroscopy (EDX) microanalysis and used to assess chemical composition of corrosion products.

\subsubsection{Electrochemical impedance spectroscopy (EIS)}

Electrochemical impedance spectroscopy was used to characterize the corrosion evolution of pre-treated $(12 \% \mathrm{HF})$, silane- $\mathrm{TiO}_{2}$ coated (AZ31_S and ZE41_S) and bi-layered (AZ31_SC, ZE41_SC, AZ31_SK, ZE41_SK) Mg alloys in simulated body fluid (SBF) at $37 \pm 1^{\circ} \mathrm{C}$ for 7 weeks. The setup, experimental conditions and chemical composition of the SBF solution are described in [20].

\section{Results}

\subsection{Surface morphology of pre-treated, sol-gel coated and bi-layered alloys}

The surface morphology of pre-treated and silane- $\mathrm{TiO}_{2}$ coated $\mathrm{AZ31}$ and $\mathrm{ZE} 41$ alloys was reported elsewhere [20]. SEM (Fig. 2a and 2b) and topographical AFM images (Fig. 2c 
and 2d) revealed that the surface of the outer collagen and chitosan layers were smooth and homogeneous with small roughness as indicated by $R q$ parameter (root mean square roughness). AFM images revealed that both collagen and chitosan top-layers consisted of aggregated nanoparticles. In the case of collagen it is an agglomeration of type I collagen molecules with average size $90 \mathrm{~nm}$.

Detailed imaging of the samples cross-section (Fig. 3) showed that the thickness of the bi-layered systems was homogeneous and reproducible, irrespectively of the alloy. The bottom sol-gel coating was $3.3 \pm 0.2 \mu \mathrm{m}$-thick and the top biopolymer layers $1.3 \pm 0.1 \mu \mathrm{m}$ thick.

\subsection{Localized impedance of the different coatings on AZ31 and ZE41 alloys}

LEIS maps during immersion in $25 \% \mathrm{SBF}$ at room temperature for $24 \mathrm{~h}$ were taken to monitor simultaneously the resistive/capacitive response of two different surface conditions on a single sample: (i) half silane- $\mathrm{TiO}_{2}$ coated and (ii) half bi-layered with solgel+biopolymer (collagen or chitosan) to determine the influence of the top-biopolymer layers on the barrier properties of the silane-based coating. Henceforth, LEIS samples will be referred as Alloy_S/SC and Alloy_S/SK alluding to the coverage of half surface with collagen or chitosan, respectively.

LEIS maps in admittance mode of AZ31_S/SC and ZE41_S/SC are depicted in Fig. 4. The midpoint in $x$ axis defines the boundary line between the two studied zones. The silane$\mathrm{TiO}_{2}$ coating corresponds to $0<x<3500$ and the silane- $\mathrm{TiO}_{2}+$ collagen to $3500<x<7000$. The admittance for the AZ31_S/SC (Fig.4a) did not show significant variations over the 24h of immersion, remaining nearly constant around $1 \times 10^{-3} \Omega^{-1} \mathrm{~cm}^{-2}$. Moreover, the collagen layer seemed to not have detrimental effects on the silane- $\mathrm{TiO}_{2}$ protective properties since there were no apparent differences in corrosion activity between S (sol-gel) and SC (solgel+collagen) sides. On the other hand, ZE41_S/SC (Fig. 4b) presented some changes with 
immersion time. At early immersion, admittance values were $\sim 7.5 \times 10^{-4} \Omega^{-1} \mathrm{~cm}^{-2}$ over the entire scanned surface. Next, admittance slightly increased to $\sim 10^{-3} \Omega^{-1} \mathrm{~cm}^{-2}$ indicating that the coating protective properties started to deteriorate, probably due to coating swelling. Still, there were no evident differences in corrosion activity between S and SC sides. However, after $24 \mathrm{~h}$ corrosion activity started to increase mainly on the SC side with some new localized active areas of higher admittance.

During the experiments, formation of blisters on the SC side of ZE41_S/SC was observed (Fig. 1b). It seemed that collagen layer trapped the evolved $\mathrm{H}_{2}$ gas avoiding it from being released into the solution. This phenomenon did not occur on the $\mathrm{S}$ side. At the neighboring of blisters (SC side) admittance values increased by a factor of 1.5 compared to the values on the $\mathrm{S}$ side.

Fig. 5 depicts LEIS maps for AZ31_S/SK and ZE41_S/SK. The admittance changes of these conditions showed a trend similar to that of samples half bi-layered with collagen. However, in the vicinity of a blister on AZ31_S/SK (Fig. 5a) admittance showed increased values. In the case of ZE41_S/SK, admittance showed the same trend as ZE41_S/SC. Nevertheless, while admittance around the blister on ZE41_S/SC reached values of $\sim 2.5 \times 10^{-3}$ $\Omega^{-1} \mathrm{~cm}^{-2}$, in ZE41_S/SK it reached values of $\sim 3.5 \times 10^{-3} \Omega^{-1} \mathrm{~cm}^{-2}$. The initial values at early immersion were $\sim 8 \times 10^{-4} \Omega^{-1} \mathrm{~cm}^{-2}$ and $\sim 7.5 \times 10^{-4} \Omega^{-1} \mathrm{~cm}^{-2}$, respectively.

\subsection{Localized corrosion behaviour of silane-TiO 2 coated $A Z 31$ and $\mathrm{ZE41}$ alloys}

Fig. 6 and Fig. 7 show the SVET current density maps and the SIET pH maps obtained over the artificial defect formed in the AZ31_S and ZE41_S coated samples, respectively. This approach allowed tracing the anodic and cathodic activities that are affected by corrosion products formation/growth in both buried and non-buried areas around the 
defect, as well as the $\mathrm{pH}$ variations that may affect the distribution and nature of such corrosion products.

Both current density and $\mathrm{pH}$ showed important variations over immersion. At the beginning of the immersion, formation of $\mathrm{H}_{2}$ gas bubbles was observed on both AZ31_S and ZE41_S samples. After 2h, the pH measured around the defect of AZ31_S was $~ 7.8$ and the $\mathrm{pH}$ measured around a gas bubble was $\sim 8.2$ (Fig. 6-1c). The corresponding SVET scan in Fig. 6-1b showed high corrosion activity after $2 \mathrm{~h}$ of immersion, reaching current density values of about $70 \mu \mathrm{A} \cdot \mathrm{cm}^{-2}$ in the anodic zone (red-orange area in colour). After $8 \mathrm{~h}$ the $\mathrm{pH}$ did not show considerable variations compared to the $\mathrm{pH}$ after $2 \mathrm{~h}$ of immersion (Fig. 6-2c). On the other hand, the anodic current density decreased to values of $\sim 40 \mu \mathrm{A} \cdot \mathrm{cm}^{-2}$ along with the formation of a cathodic zone (blue area in colour) at the defect (Fig. 6-2b). Both cathodic and anodic zones at the defect increased after $24 \mathrm{~h}$, with a slight increase of the anodic current density up to $\sim 55 \mu \mathrm{A} \cdot \mathrm{cm}^{-2}$ (Fig. 6-3b). New anodic areas appeared due to the formation of pits on the substrate (arrow in Fig. 6-3a). After 24h there were no relevant $\mathrm{pH}$ gradients over the scanned area of AZ31_S with a steady $\mathrm{pH}$ value of $~ 7.4$.

In the case of $\mathrm{ZE} 41 \_\mathrm{S}$ the $\mathrm{pH}$ variations showed a similar trend when compared to AZ31_S; however, there was still a pH gradient evidenced after 24h (Fig. 7-3c). Initially, alkalinization around the defect along with formation of $\mathrm{H}_{2}$ bubbles was observed. Next, as immersion elapsed the $\mathrm{pH}$ values around the defect gradually decreased from $\sim 8.1$ at $2 \mathrm{~h}$ (Fig. 7-1c) to $\sim 7.8$ at 24 h (Fig. 7-3c). SVET maps showed that the difference between the highest anodic current density values (red-orange) and the lowest cathodic current density values (blue) of ZE41_S was $80 \mu \mathrm{A} \cdot \mathrm{cm}^{-2}$ after 2h (Fig. 7-1b). Concomitantly, the difference between anodic and cathodic current densities of AZ31_S was $120 \mu \mathrm{A} \cdot \mathrm{cm}^{-2}$ for the same immersion 
time. The larger difference between anodic and cathodic current density values for AZ31_S suggests that this sample, at this stage, had higher corrosion activity than ZE41_S.

Fig. 8 shows SEM images of the artificial defects on silane- $\mathrm{TiO}_{2}$ coated alloys completely covered by corrosion products rich in $\mathrm{Ca}$ and $\mathrm{P}$ after $24 \mathrm{~h}$ of exposure to the corrosive medium, showing that formation of the corrosion layer already takes place at early stages of immersion.

\subsection{Corrosion evolution of bi-layered AZ31 and ZE41 alloys with collagen and chitosan}

The corrosion behavior of the bi-layered systems was characterized by EIS experiments at open circuit potential (OCP) in SBF at $37 \pm 1^{\circ} \mathrm{C}$. Fig. 9 shows the OCP evolution of the bi-layered alloys along with representative Bode plots obtained for each condition during 7 weeks of immersion. Some differences on the corrosion response of AZ31_SC and ZE41_SC were observed, particularly at longer immersion times. First, low impedance values gradually decreased between $2 \mathrm{~h}$ and 2 weeks. The sol-gel/collagen (SC) coating response was similar on both alloys (Fig. 9b-c). However, after 4 weeks impedance of AZ31_SC sharply increased by four orders of magnitude to values $\sim 5 \times 10^{8} \Omega \mathrm{cm}^{2}$. The shape of the impedance plot and the high frequency $\left(10^{3}-10^{5} \mathrm{~Hz}\right)$ phase angle value close to 90 of AZ31_SC (Fig. 9b), indicate the formation of a protective layer of corrosion products that displays a capacitive behavior in the high frequency range. In the case of ZE41_SC, the impedance modulus measured after 4 weeks $\left(\sim 6 \times 10^{4} \Omega \mathrm{cm}^{2}\right)$ suggests that the corrosion layer formed was much less protective than that of AZ31_SC.

EIS results of bi-layered alloys suggested that collagen and chitosan top-layers do not have a detrimental effect on the barrier properties of the silane- $\mathrm{TiO}_{2}$. In the case of $\mathrm{AZ31}$ _SC and AZ31_SK, low frequency impedance values were higher than that of AZ31_S at early 
immersion. In the case of ZE41_SC and ZE41_SK, impedance modulus behaves close to that of ZE41_S.

\subsection{Morphology and composition of corroded surfaces after EIS}

Fig. 10 shows some SEM micrographs and EDX analysis of AZ31_SC, ZE41_SC, AZ31_SK and ZE41_SK corroded substrates at selected regions after 7 weeks in SBF. Deep corrosion attack is observed for all conditions. The cracks in all surfaces resulted from the corrosion layers shrinkage during dehydration, as well as from the vacuum atmosphere inside the SEM chamber.

The EDX results suggested that the corrosion products of AZ31_SC are composed of: (i) an inner-most layer mainly formed by magnesium hydroxide and magnesium carbonate $\left(\mathrm{Mg}(\mathrm{OH})_{2} / \mathrm{MgCO}_{3}\right)$ with some $\mathrm{Al}$ and $\mathrm{Zn}$ content (Fig. 10a, +3$)$; (ii) an intermediate layer with the same components above-mentioned but with a reduced $\mathrm{Mg}$ content and an increased $\mathrm{C}$ and $\mathrm{O}$ content $($ Fig. 10a, +2$)$. Low quantities of $\mathrm{Ca}, \mathrm{P}$ and $\mathrm{Cl}$ were detected in this layer too; (iii) on top of the intermediate layer, islets of Ca-O-C aggregates suggest the presence of $\mathrm{CaCO}_{3}$ randomly distributed over the surface $($ Fig. $10 a,+1)$.

The corrosion products of ZE41_SC consisted of (i) an inner-most layer of calcium carbonate $\left(\mathrm{CaCO}_{3}\right)$ sphero-aggregates with some $\mathrm{Mg}$ content $(\mathbf{F i g}$. 10b, +4) and (ii) a rather smooth outer-most layer whose composition suggests the presence of $\mathrm{Mg}(\mathrm{OH})_{2} / \mathrm{MgCO}_{3}$ with some traces of $\mathrm{P}, \mathrm{Cl}$ and $\mathrm{Zn}(\mathbf{F i g} . \mathbf{1 0 b},+5)$.

The chemical analyses suggested that corrosion products of AZ31_SK are formed by: (i) a bottom layer of $\mathrm{Mg}(\mathrm{OH})_{2} / \mathrm{MgCO}_{3}$ and (ii) a top layer of $\mathrm{CaCO}_{3}$. This top layer was not continuous and covered a small fraction of the overall surface (Fig. 10c, +2 ). On the other hand, EDX results suggested that the corrosion products of ZE41_SK consisted of a layer of 
combined $\mathrm{Mg}(\mathrm{OH})_{2} / \mathrm{MgCO}_{3}$ with decreasing $\mathrm{Ca}$ and $\mathrm{P}$ content and increasing $\mathrm{Cl}$ content outwards the surface.

X-ray diffraction (XRD) measurements were attempted to get further insights in the composition of the corrosion products. XRD evidenced only peaks from the Mg substrate that were detected for all tested conditions, suggesting that the corrosion layers formed on the alloys are predominantly amorphous.

\section{Discussion}

Mg alloys have been proposed as suitable materials to fabricate biodegradable implants for bone repair applications [10,24]. One outstanding advantage of $\mathrm{Mg}$ alloys over other types of biomaterials is their good bioactivity and release of non-toxic species [2]. However, their intrinsic high reactivity in aqueous solutions demands for designing tailored surface functionalization methods to produce the desired implant surface able to stimulate new bone formation and cell proliferation. Elucidating the degradation mechanisms of an implant is of primary importance since all phenomena occurring at the implant/tissue interface may redefine both the implant performance and the surrounding tissue. Here, we propose a multi-level approach in order to determine the corrosion evolution of AZ31 and ZE41 Mg alloys functionalized with bi-layered silane- $\mathrm{TiO}_{2} /$ biopolymers coatings. Collagen and chitosan are selected for improving both corrosion resistance and biological responses of $\mathrm{Mg}$ alloys.

Previously, it was demonstrated that the hybrid silane- $\mathrm{TiO}_{2}$ coating enhanced corrosion resistance of the $\mathrm{Mg}$ alloys in SBF, playing a determinant role in the composition of the corrosion products [20]. A poorly crystalline $\mathrm{Mg}(\mathrm{OH})_{2} /$ hydroxyapatite corrosion layer enriched in calcium and phosphate comparatively to the corrosion layer of pre-treated alloys was identified [20]. SVET results showed that the nature of the alloying elements influences the current density values and the size and distribution of anodic and cathodic regions. More intense anodic activity was observed on AZ31_S comparatively to ZE41_S (Fig. 6 and Fig. 
7), an effect that can be attributed to the presence of rare-earths in the alloy composition. Rare-earth elements are well known as corrosion inhibitors for aluminum, ferrous and zinc alloys [25]. In $\mathrm{Mg}$ alloys $\mathrm{Ce}^{3+}$ ions provide corrosion protection in a wide $\mathrm{pH}$ range, from 5.5 to 12 [25]. By SVET measurements, Karavai et al. [25] demonstrated that local current densities on an artificial defect in a sol-gel coated AZ31 alloy in $0.05 \mathrm{M} \mathrm{NaCl}$ supplemented with $0.01 \mathrm{M} \mathrm{Ce}\left(\mathrm{NO}_{3}\right)_{3}$, were significantly suppressed compared to the same condition in a $0.05 \mathrm{M} \mathrm{NaCl}$ solution alone.

Anodic dissolution is accompanied by hydrogen evolution $\left(\mathrm{H}_{\mathrm{evo}}\right)$ at cathodic sites leading to local alkalinization of the solution. SIET results showed that local alkalinization of the solution on AZ31_S was suppressed after 24h (Fig.6-3c), while on ZE41_S it remained for a longer time (Fig. 7-3c). These results are in accordance with the reduced $\mathrm{H}_{\mathrm{evo}}$ of $\mathrm{Zn}$-rich Mg alloys reported by Chen and Thouas [3] and with the hypothesis of increased $\mathrm{H}_{\mathrm{evo}}$ due to the presence of elements nobler than $\mathrm{Mg}$ in the corrosion products layer postulated by Thomas et al. [26].

Numerical fitting of EIS data was carried out using the equivalent circuit depicted in Fig. 11a. Constant phase elements (CPE) were used instead of pure capacitors. $\mathrm{R}_{\mathrm{SC} / \mathrm{SK}}$ and $\mathrm{CPE}_{\mathrm{SC} / \mathrm{SK}}$ represent the resistance and capacitive response of the bi-layered coating with either collagen or chitosan, respectively. In the same way $\mathrm{R}_{\mathrm{IL}}$ and $\mathrm{CPE}$ IL account for the resistance and capacitive response of the interfacial layer (IL) of corrosion products, respectively. $R_{c t}$ and $\mathrm{CPE}_{\mathrm{dl}}$ represent the charge transfer resistance and the dual layer capacitance, respectively. The $\chi^{2}$ of the regression was around $10^{-3}$.

A sharp increase in resistance values of AZ31_SC after 3 weeks of immersion was observed. $\mathrm{R}_{\mathrm{IL}}$ increase is due to the formation of the dense layer of corrosion products as observed in Fig. 10a. It has been already discussed by other authors [27] that Al-containing $\mathrm{Mg}$ alloys when corroding can built $\mathrm{Al}_{2} \mathrm{O}_{3}$ into the corrosion products layer. Despite some $\mathrm{Al}$ 
was detected on the corrosion layer of AZ31_SC, the O-to-Al ratio is too high for considering that $\mathrm{Al}_{2} \mathrm{O}_{3}$ was formed. Other authors have reported formation of $\mathrm{Al}(\mathrm{OH})_{3}$ together with $\mathrm{Al}_{2} \mathrm{O}_{3}$ into the corrosion products of $\mathrm{Al}$-rich $\mathrm{Mg}$ alloys [28].

Zeng et al. [29] proposed a six steps model involving $\mathrm{Mg}(\mathrm{OH})_{2}$ and $\mathrm{MgCO}_{3}$ formation mechanisms into the corrosion film of an AZ31 alloy in saline solutions with additions $\mathrm{of}^{-}$, $\mathrm{HCO}_{3}^{-}, \mathrm{HPO}_{4}^{2-}$ and $\mathrm{SO}_{4}^{2-}$. First, electrochemical dissolution of $\mathrm{Mg}$ and donation of electrons and the water-induced decomposition by electron capture and $\mathrm{H}_{\text {evo }}$ take place (Eq. 3 and Eq. 1 in [20]). Next, hydrolysis of $\mathrm{HCO}_{3}^{-}$followed by the formation of $\mathrm{MgCO}_{3}$ as follows [29]: $\mathrm{HCO}_{3}^{-}+\mathrm{H}_{2} \mathrm{O} \leftrightarrow \mathrm{H}_{2} \mathrm{CO}_{3}+\mathrm{OH}^{-}$ (Eq. 1)

$\mathrm{Mg}^{2+}+\mathrm{HCO}_{3}^{-}+\mathrm{OH}^{-}+(\mathrm{x}-1) \mathrm{H}_{2} \mathrm{O} \leftrightarrow \mathrm{MgCO}_{3} \cdot \mathrm{xH}_{2} \mathrm{O}(\mathrm{x}=3,5)$

$2 \mathrm{Mg}^{2+}+\mathrm{CO}_{3}^{2-}+2 \mathrm{OH}^{-} \leftrightarrow \mathrm{Mg}(\mathrm{OH})_{2} \downarrow+\mathrm{MgCO}_{3} \downarrow$

during this period $\left[\mathrm{Mg}^{2+}\right]$ and $\left[\mathrm{OH}^{-}\right]$continuously increase while $\left[\mathrm{HCO}_{3}^{-}\right]$decreases and, consequently, only $\mathrm{Mg}(\mathrm{OH})_{2}$ forms (Eq. 4 in [20]) [29]. Finally, the dissolution of $\mathrm{Mg}(\mathrm{OH})_{2}$ through the reaction with chloride according to the next reaction [29]:

$\mathrm{Mg}(\mathrm{OH})_{2}+2 \mathrm{Cl}^{-} \rightarrow \mathrm{MgCl}_{2}+2 \mathrm{OH}^{-}$

Since the presence of C was not detected on the corrosion layer of neither AZ31_S nor ZE41_S [20], it may be presumed that collagen layer changes the amount of $\mathrm{HCO}_{3}^{-}$ions present in solution. This can be attributed to the ability of the protein to modify the local $\mathrm{pH}$ and/or ionic equilibria, for instance via $\mathrm{Mg}^{2+} / \mathrm{Ca}^{2+}$ binding. Xin et al. [28] stated that $\mathrm{HCO}_{3}^{-}$ ions can stimulate corrosion of $\mathrm{Mg}$ alloys during early immersion but also induce rapid surface passivation due to the precipitation of $\mathrm{MgCO}_{3}$ in the corrosion products that can 
subsequently inhibit pitting corrosion [28]. The latter may explain the high $\mathrm{R}_{\mathrm{IL}}$ and $\mathrm{R}_{\mathrm{ct}}$ values of AZ31_SC after 3 weeks of immersion.

Same as AZ31_SC, the high C content detected in the ZE41_SC (Fig. 10b) corrosion products is expected to come from the collagen layer. Retting et al. [30] demonstrated that during corrosion degradation of a Mg-RE alloy in modified SBF (m-SBF) a considerable fraction of $\mathrm{Ca}$ was replaced by $\mathrm{Mg}$ in the corrosion layer. This may explain the $\mathrm{Mg}$ content in the $\mathrm{CaCO}_{3}$ spheroaggregates of ZE41_SC. Other authors have discussed that $\mathrm{CaCO}_{3}$ is the predominant product under stable temperature conditions and around $\mathrm{pH}$ values of 11 [31]. The $\mathrm{pH}$ evolution determined by SIET showed that the $\mathrm{pH}$ around the artificial defect of ZE41_S reached maximum values of $\sim 8.0$. However, in the buried areas where the substrate is not in direct contact with the electrolyte the $\mathrm{pH}$ is expected to reach higher values. That is the case of bi-layered alloys where formation of $\mathrm{H}_{2}$ gas pockets was observed. On the other hand, Jamesh et al. [32] stated that the corrosion layer composition of a rare-earth containing $\mathrm{Mg}$ alloy changes over time. The authors demonstrated that initial grow and posterior densification and thickening of $\mathrm{CaCO}_{3}$ occurred on a ZM21 alloy whereas thickening was delayed for pure $\mathrm{Mg}$. This may be an indication that $\mathrm{Zn}$ influences precipitation and growth of $\mathrm{CaCO}_{3}$ during the first stages of immersion. The wide variations in $\mathrm{R}_{\mathrm{IL}}$ and $\mathrm{CPE}_{\mathrm{IL}}$ of ZE41_SC and ZE41_SK are probably due to variations in the corrosion layer composition as stated by Jamesh et al. [32]. Fitting results plotted in Fig. 11 showed that stabilization of the corrosion products layer takes place faster on ZE41_SK than on ZE41_SC. CPE 
ZE41_SK showed few variations during the immersion period (Fig. 11e). Same was the case of AZ31_SK as compared with its analogous condition with collagen.

EDX analysis of silane- $\mathrm{TiO}_{2} /$ collagen coatings after EIS experiments (not shown) revealed the presence of $\mathrm{Mg}, \mathrm{C}$ and $\mathrm{O}$ on the coating surface of both AZ31_SC and ZE41_SC. In the case of ZE41_S some Ca and P were detected on the coating surface too [20]. Chemical analysis by $\mathrm{EDX}$ (not shown) suggests that the deposits are probably $\mathrm{MgCO}_{3}$-collagen composites. It may be presumed that the $\mathrm{Mg}^{2+}$ ions in solution originating from substrate dissolution are adsorbed onto the surface of the coating to form $\mathrm{MgCO}_{3}$. Some studies [33] have demonstrated that modified $\mathrm{Mg}^{2+}$ ions on the apatite crystals mixed with collagen improved osteoblasts adhesion in respect to the same composite without Mg. Thus, precipitation of $\mathrm{MgCO}_{3}$ on the coating surface of AZ31_SC and ZE41_SC may favour adhesion of osteoblasts onto these layers. Precipitation of $\mathrm{MgCO}_{3}$ onto the dual-layer coatings with chitosan was also found. The formation of $\mathrm{MgCO}_{3}$ may be explained by the same mechanisms already described in the cases with collagen.

Then, from the results previously reported in [20] we demonstrated that $\mathrm{CaP}$ composites are deposited onto the corrosion products of both sol-gel coated AZ31 and ZE41 alloys and that the presence of the silane- $\mathrm{TiO}_{2}$ coating determines the Ca-to-P ratio of those composites. However, the presence of collagen and chitosan as top-most layers strongly influences the composition of the corrosion products of AZ31 and ZE41 Mg alloys. Carbonated compounds were built into the corrosion products resulting in additional 
corrosion protection to the substrate. Particularly the corrosion layer of AZ31_SC showed effective corrosion protection to the alloy, reaching impedance values four orders of magnitude larger than the remaining conditions.

Besides the demonstration of the ability of bifunctional coatings to control the corrosion behavior of $\mathrm{Mg}$ alloys, our results can also be considered from an in vivo perspective. In fact, the biopolymer layer that was here deposited on purpose can also mimic the presence of tissues surrounding the implanted material. Therefore, our results suggest that these tissues can redefine the corrosion behavior and hence the corrosion products of $\mathrm{Mg}$ alloys. It can also be foreseen that the presence of cells will also impact on the corrosion processes, an issue that will be further detailed in future work.

\section{Conclusions}

Bi-layered silane- $\mathrm{TiO}_{2} /$ biopolymer coatings were developed to functionalize the surface of AZ31 and ZE41 Mg alloys intended for bone repair applications. The hybrid silane$\mathrm{TiO}_{2}$ coating provided effective corrosion protection to the $\mathrm{Mg}$ alloys. Collagen and chitosan biopolymers were added as top-most layers to functionalize the silane- $\mathrm{TiO}_{2}$ coating for increased biocompatibility. The results showed that the presence of the biopolymers strongly influenced the composition of the corrosion products of both materials. When collagen or chitosan were present, carbonated phases such as $\mathrm{MgCO}_{3}$ and $\mathrm{CaCO}_{3}$ were formed as corrosion products providing additional corrosion protection to the $\mathrm{Mg}$ alloys at longer immersion times (> 3 weeks). LEIS results showed that the biopolymer layer provided additional corrosion protection compared to the silane- $\mathrm{TiO}_{2}$ coating alone. Furthermore, collagen and chitosan top-layers trap the evolved $\mathrm{H}_{2}$ gas forming gas pockets. In practical 
terms, this suggests that $\mathrm{Mg}$ implants coated with the here proposed bi-layered systems would delay hydrogen gas from being released. The results evidenced that silane-based bi-layered coatings with collagen and chitosan are a promising route to functionalize AZ31 and ZE41 alloys for enhanced biointegration. In parallel, the here reported findings contribute to elucidate the corrosion evolution of $\mathrm{Mg}$ alloys in biologically-relevant conditions in the long term.

\section{Acknowledgements}

The authors acknowledge the financial support of the project 2012-05-EM from the International Doctoral School in Functional Materials IDS-FunMat and the financial support by Fundacão para a Ciência e a Tecnologia (FCT) to CQE (UID/QUI/00100/2013). They thank Dr C. Hélary (LCMCP) for fruitful discussions. 


\section{References}

[1] H. Hermawan, D. Mantovani, Degradable metallic biomaterials: the concept, current developments and future directions, MINERVA BIOTEC. 21 (2009) 207-16.

[2] F. Witte, V. Kaese, H. Haferkamp, E. Switzer, a. Meyer-Lindenberg, C.J. Wirth, et al., In vivo corrosion of four magnesium alloys and the associated bone response, Biomaterials. 26 (2005) 3557-3563. doi:10.1016/j.biomaterials.2004.09.049.

[3] Q. Chen, G.A. Thouas, Metallic implant biomaterials, Mater. Sci. Eng. R Reports. 87 (2015) 1-57. doi:10.1016/j.mser.2014.10.001.

[4] Dean Carolyn, The miracle of Magnesium, 1st ed., The Random House Publishing Group, New York, 2003.

[5] A.M. Fekry, R.M. El-sherif, Electrochemical corrosion behavior of magnesium and titanium alloys in simulated body fluid, Electrochim. Acta. 54 (2009) 7280-7285. doi:10.1016/j.electacta.2009.07.047.

[6] Z. Zhen, T.F. Xi, Y.F. Zheng, A review on in vitro corrosion performance test of biodegradable metallic materials, Trans. Nonferrous Met. Soc. China (English Ed. 23 (2013) 2283-2293. doi:10.1016/S1003-6326(13)62730-2.

[7] F. Witte, J. Fischer, J. Nellesen, H.-A. Crostack, V. Kaese, A. Pisch, et al., In vitro and in vivo corrosion measurements of magnesium alloys, Biomaterials. 27 (2006) 10131018. doi:10.1016/j.biomaterials.2005.07.037.

[8] J. Hofstetter, E. Martinelli, A.M. Weinberg, M. Becker, B. Mingler, P.J. Uggowitzer, et al., Assessing the degradation performance of ultrahigh-purity magnesium in vitro and in vivo, Corros. Sci. 91 (2015) 29-36. doi:10.1016/j.corsci.2014.09.008.

[9] J. Hofstetter, E. Martinelli, S. Pogatscher, P. Schmutz, E. Povoden-Karadeniz, a. M. Weinberg, et al., Influence of trace impurities on the in vitro and in vivo degradation of biodegradable $\mathrm{Mg}-5 \mathrm{Zn}-0.3 \mathrm{Ca}$ alloys, Acta Biomater. 23 (2015) 0-6.

doi:10.1016/j.actbio.2015.05.004.

[10] N.T. Kirkland, J. Lespagnol, N. Birbilis, M.P. Staiger, A survey of bio-corrosion rates of magnesium alloys, Corros. Sci. 52 (2010) 287-291.

doi:10.1016/j.corsci.2009.09.033.

[11] C.Y. Wu, J. Zhang, State-of-art on corrosion and protection of magnesium alloys based on patent literatures, Trans. Nonferrous Met. Soc. China (English Ed. 21 (2011) 892902. doi:10.1016/S1003-6326(11)60799-1.

[12] I.-Y. Kim, S.-J. Seo, H.-S. Moon, M.-K. Yoo, I.-Y. Park, B.-C. Kim, et al., Chitosan and its derivatives for tissue engineering applications, Biotechnol. Adv. 26 (2008) 121. doi:10.1016/j.biotechadv.2007.07.009.

[13] F.-M. Chen, X. Liu, Advancing biomaterials of human origin for tissue engineering, Prog. Polym. Sci. (2015). doi:10.1016/j.progpolymsci.2015.02.004.

[14] D. Mushahary, C. Wen, J.M. Kumar, J. Lin, N. Harishankar, P. Hodgson, et al., Collagen type-I leads to in vivo matrix mineralization and secondary stabilization of 
Mg-Zr-Ca alloy implants, Colloids Surfaces B Biointerfaces. 122 (2014) 719-728. doi:10.1016/j.colsurfb.2014.08.005.

[15] Z.L. Wang, Y.H. Yan, T. Wan, H. Yang, Poly(L-lactic acid)/hydroxyapatite/collagen composite coatings on AZ31 magnesium alloy for biomedical application, Proc. Inst. Mech. Eng. H. 227 (2013) 1094-103. doi:10.1177/0954411913493845.

[16] A.M. Fekry, Electrochemical behavior of a novel nano-composite coat on Ti alloy in phosphate buffer solution for biomedical applications, RSC Adv. 6 (2016) 2027620285. doi:10.1039/C6RA01064D.

[17] A.M. Fekry, A.A. Ghoneim, M.A. Ameer, Electrochemical impedance spectroscopy of chitosan coated magnesium alloys in a synthetic sweat medium, Surf. Coatings Technol. 238 (2014) 126-132. doi:10.1016/j.surfcoat.2013.10.058.

[18] S. Kunjukunju, A. Roy, M. Ramanathan, B. Lee, J.E. Candiello, P.N. Kumta, A layerby-layer approach to natural polymer-derived bioactive coatings on magnesium alloys, Acta Biomater. 9 (2013) 8690-8703. doi:10.1016/j.actbio.2013.05.013.

[19] J. Wang, J. Tang, P. Zhang, Y. Li, J. Wang, Y. Lai, et al., Surface modification of magnesium alloys developed for bioabsorbable orthopedic implants: A general review, J. Biomed. Mater. Res. Part B Appl. Biomater. 100B (2012) 1691-1701. doi:10.1002/jbm.b.32707.

[20] L.C. Córdoba, M.F. Montemor, T. Coradin, Silane/TiO2 coating to control the corrosion rate of magnesium alloys in simulated body fluid, Corros. Sci. 104 (2016) 152-161. doi:10.1016/j.corsci.2015.12.006.

[21] C. Helary, A. Foucault-Bertaud, G. Godeau, B. Coulomb, M.M. Giraud Guille, Fibroblast populated dense collagen matrices: Cell migration, cell density and metalloproteinases expression, Biomaterials. 26 (2005) 1533-1543. doi:10.1016/j.biomaterials.2004.05.016.

[22] M.G. Taryba, S. V. Lamaka, D. V. Snihirova, M.G.S. Ferreira, M.F. Montemor, W.K. Wijting, et al., The combined use of scanning vibrating electrode technique and micropotentiometry to assess the self-repair processes in defects on smart coatings applied to galvanized steel, Electrochim. Acta. 56 (2011) 4475-4488.

doi:10.1016/j.electacta.2011.02.048.

[23] K. Aoki, Nernst equation complicated by electric random percolation at conducting polymer-coated electrodes, J. Electroanal. Chem. Interfacial Electrochem. 310 (1991) 1-12. doi:10.1016/0022-0728(91)85247-M.

[24] M.P. Staiger, A.M. Pietak, J. Huadmai, G. Dias, Magnesium and its alloys as orthopedic biomaterials: A review, Biomaterials. 27 (2006) 1728-1734. doi:10.1016/j.biomaterials.2005.10.003.

[25] O. V. Karavai, A.C. Bastos, M.L. Zheludkevich, M.G. Taryba, S. V. Lamaka, M.G.S. Ferreira, Localized electrochemical study of corrosion inhibition in microdefects on coated AZ31 magnesium alloy, Electrochim. Acta. 55 (2010) 5401-5406. doi:10.1016/j.electacta.2010.04.064.

[26] S. Thomas, N.V. Medhekar, G.S. Frankel, N. Birbilis, Corrosion mechanism and 
hydrogen evolution on Mg, Curr. Opin. Solid State Mater. Sci. 19 (2015) 85-94. doi:10.1016/j.cossms.2014.09.005.

[27] Y. Xin, T. Hu, P.K. Chu, In vitro studies of biomedical magnesium alloys in a simulated physiological environment: A review, Acta Biomater. 7 (2011) 1452-1459. doi:10.1016/j.actbio.2010.12.004.

[28] Y. Xin, K. Huo, H. Tao, G. Tang, P.K. Chu, Influence of aggressive ions on the degradation behavior of biomedical magnesium alloy in physiological environment, Acta Biomater. 4 (2008) 2008-2015. doi:10.1016/j.actbio.2008.05.014.

[29] R.C. Zeng, Y. Hu, S.K. Guan, H.Z. Cui, E.H. Han, Corrosion of magnesium alloy AZ31: The influence of bicarbonate, sulphate, hydrogen phosphate and dihydrogen phosphate ions in saline solution, Corros. Sci. 86 (2014) 171-182.

doi:10.1016/j.corsci.2014.05.006.

[30] R. Rettig, S. Virtanen, Composition of corrosion layers on a magnesium rare-earth alloy in simulated body fluids, J. Biomed. Mater. Res. - Part A. 88 (2007) 359-369. doi:10.1002/jbm.a.31887.

[31] F.C. Tai, Clifford Y., Polymorphism of $\mathrm{CaCO} 3$, precipitated in a constantcomposition environment, AIChE J. 44 (1998) 1790-1798.

[32] M. Jamesh, S. Kumar, T.S.N.S. Narayanan, Corrosion behavior of commercially pure $\mathrm{Mg}$ and ZM21 Mg alloy in Ringer' s solution - Long term evaluation by EIS, Corros. Sci. 53 (2011) 645-654. doi:10.1016/j.corsci.2010.10.011.

[33] Y. Yamasaki, Y. Yoshida, M. Okazaki, a. Shimazu, T. Uchida, T. Kubo, et al., Synthesis of functionally graded $\mathrm{MgCO} 3$ apatite accelerating osteoblast adhesion, J. Biomed. Mater. Res. 62 (2002) 99-105. doi:10.1002/jbm.10220. 


\section{List of figure captions}

Fig. 1. (a) Schematic view of sample setup and scanned area. (b) Photography of the real assembly during LEIS experiments (S: sol-gel, SC: sol-gel+collagen, SK: sol-gel+chitosan).

Fig. 2. Representative SEM images of (a) AZ31_SC and (b) ZE41_SK (scale bar $10 \mu \mathrm{m}$ ). Topographical AFM images of (c) ZE41_SC and (d) AZ31_SK $\left(R_{q}\right.$ : root mean square roughness, measured by AFM).

Fig. 3. Cross-sectional SEM micrograph of the bi-layered coatings deposited on the Mg alloys.

Fig. 4. LEIS maps of (a) AZ31_S/SC and (b) ZE41_S/SC at different immersion times in $25 \%$ SBF for $24 \mathrm{~h}$. Maps recorded at different time points are shifted upwards with the time progress (S: sol-gel, SC: solgel+collagen)

Fig. 5. LEIS maps of (a) AZ31_S/SK and (b) ZE41_S/SK at different immersion times in $25 \%$ SBF for $24 \mathrm{~h}$. Maps recorded at different time points are shifted upwards with the time progress (S: sol-gel, SK: solgel+chitosan).

Fig. 6. Current density (1b, 2b, 3b) and pH distribution (1c, 2c, 3c) at the surface of AZ31_S around the artificial defect upon exposure to the SBF solution at room temperature $\left(\sim 22^{\circ} \mathrm{C}\right)$ for $24 \mathrm{~h}$. The dashed line in 1 a indicates the scanned area.

Fig. 7. Current density $(1 b, 2 b, 3 b)$ and pH distribution $(1 c, 2 c, 3 c)$ at the surface of ZE41_S around the artificial defect upon exposure to the SBF solution at room temperature $\left(\sim 22^{\circ} \mathrm{C}\right)$ for $24 \mathrm{~h}$.

Fig. 8. SEM images of the artificial defect for SVET/SIET experiments on (1a) AZ31_S and (2a) ZE41_S after $24 \mathrm{~h}$ of exposure to SBF at room temperature. Elemental distribution maps (1b-1d and $2 \mathrm{~b}-2 \mathrm{~d})$ and EDX spectra (1e and 2e) of previously defined elements over the scanned area of AZ31_S and ZE41_S, respectively.

Fig. 9. (a) OCP evolution and Bode plots of (b) AZ31_SC, (c) ZE41_SC, (d) AZ31_SK and (e) ZE41_SK immersed in SBF at $37 \pm 1^{\circ} \mathrm{C}$ for 7 weeks. Symbols are impedance values $|\mathrm{Z}|$, lines are phase angle values $(\phi)$.

Fig. 10. Morphology of corroded substrates of (a) AZ31_SC, (b) ZE41_SC, (c) AZ31_SK and (d) ZE41_SK after EIS experiments in SBF at $37 \pm 1^{\circ} \mathrm{C}$ for 7 weeks and EDX results.

Fig. 11. (a) Equivalent circuit used to fit EIS data of bi-layered $\mathrm{Mg}$ alloys. Evolution of the resistance and CPE parameter Q for (b) AZ31_SC, (c) ZE41_SC, (d) AZ31_SK and (e) ZE41_SK, respectively. Symbols are resistance values and lines the corresponding CPE values (IL: interfacial layer, ct: charge transfer resistance, dl: double layer capacitance). 


\section{Figures}

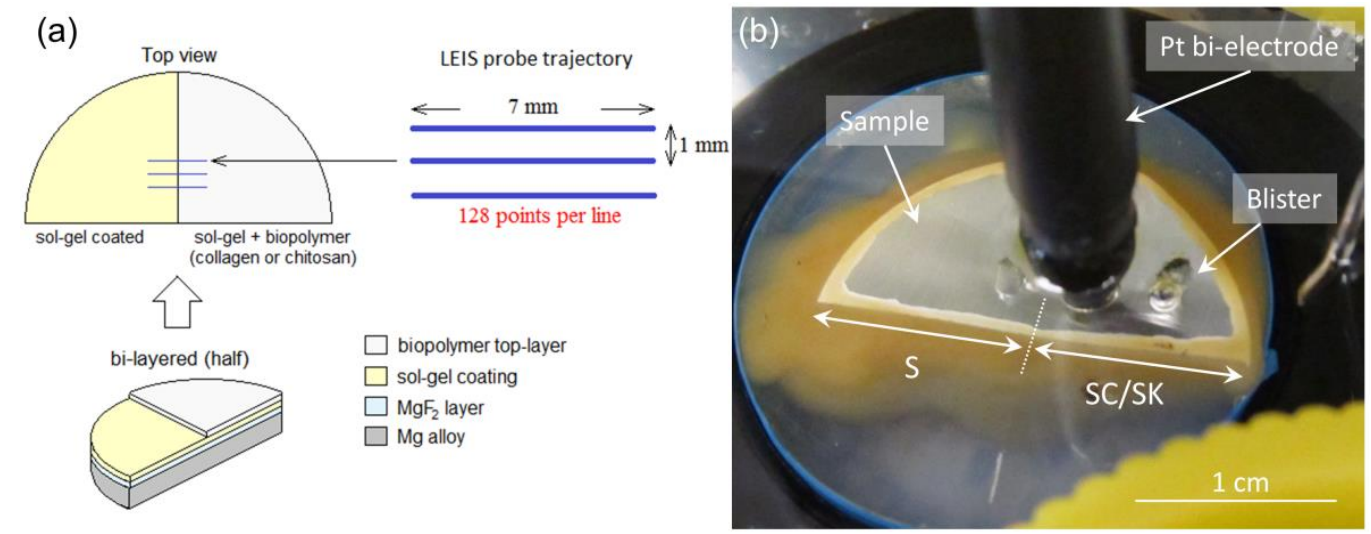

Fig. 1 


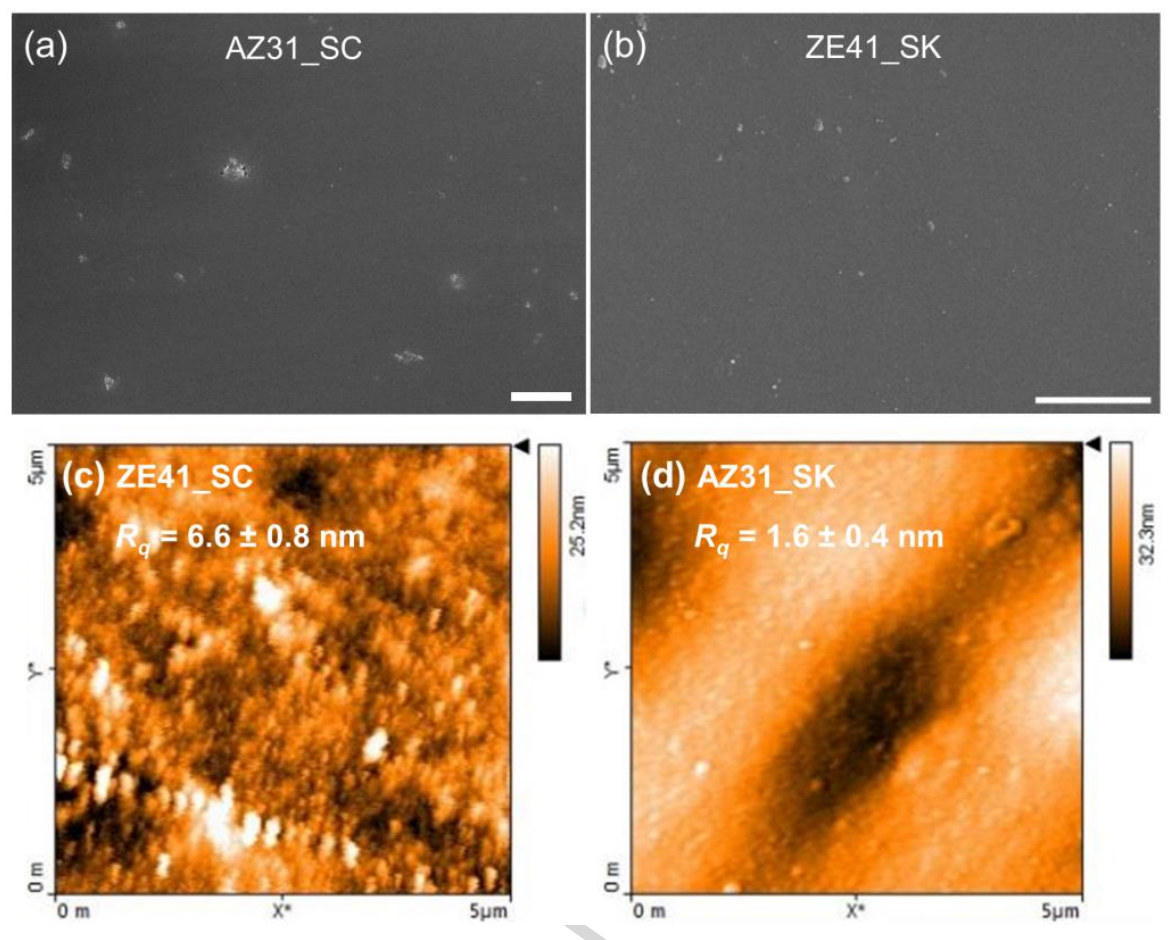

Fig. 2 


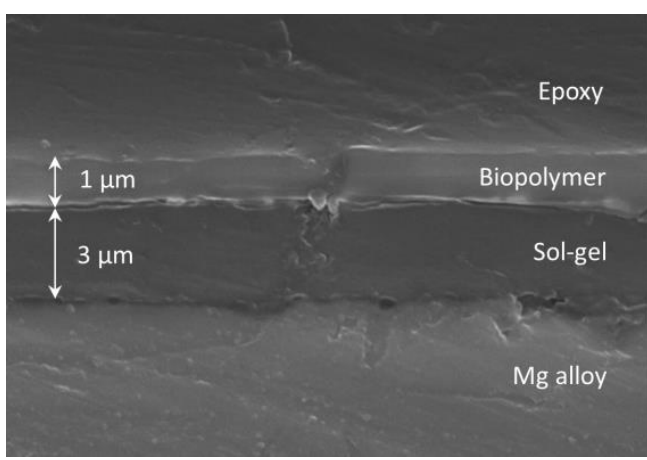

Fig. 3 

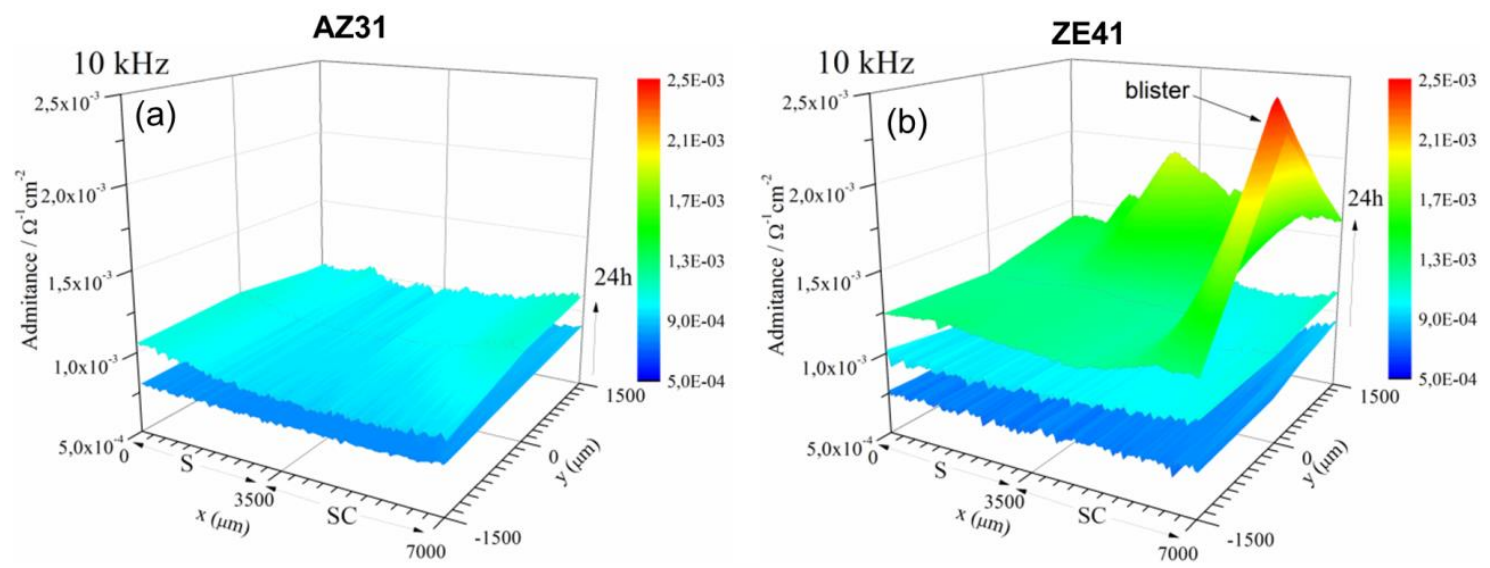

Fig. 4 

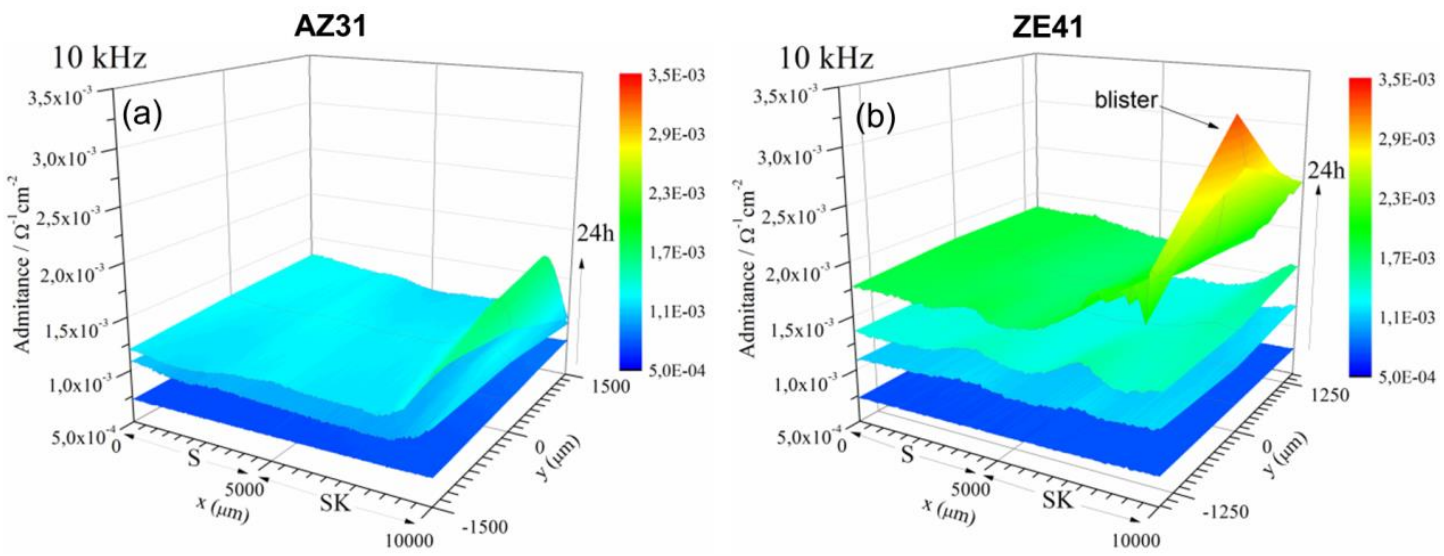

Fig. 5 

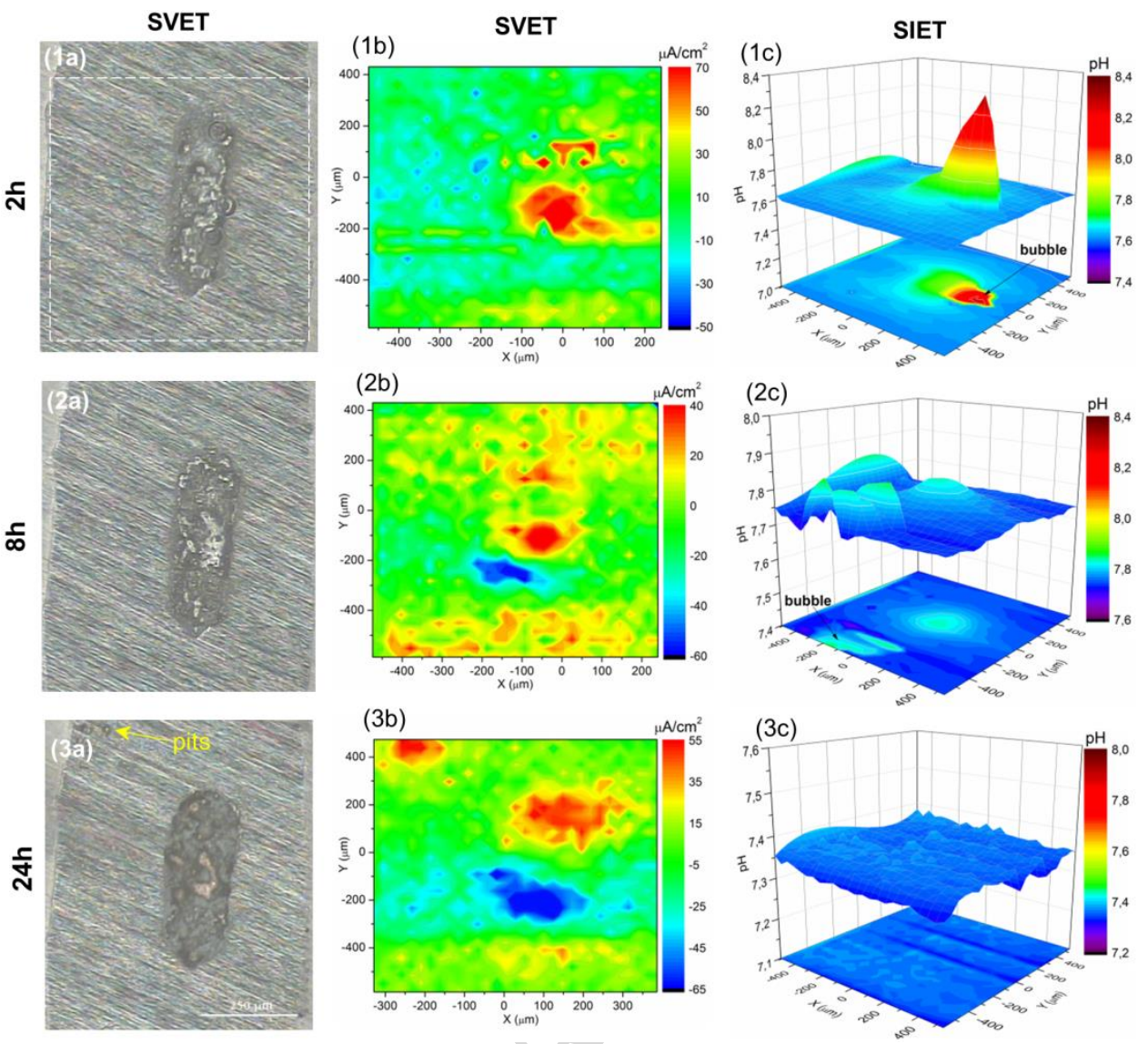

Fig. 6 

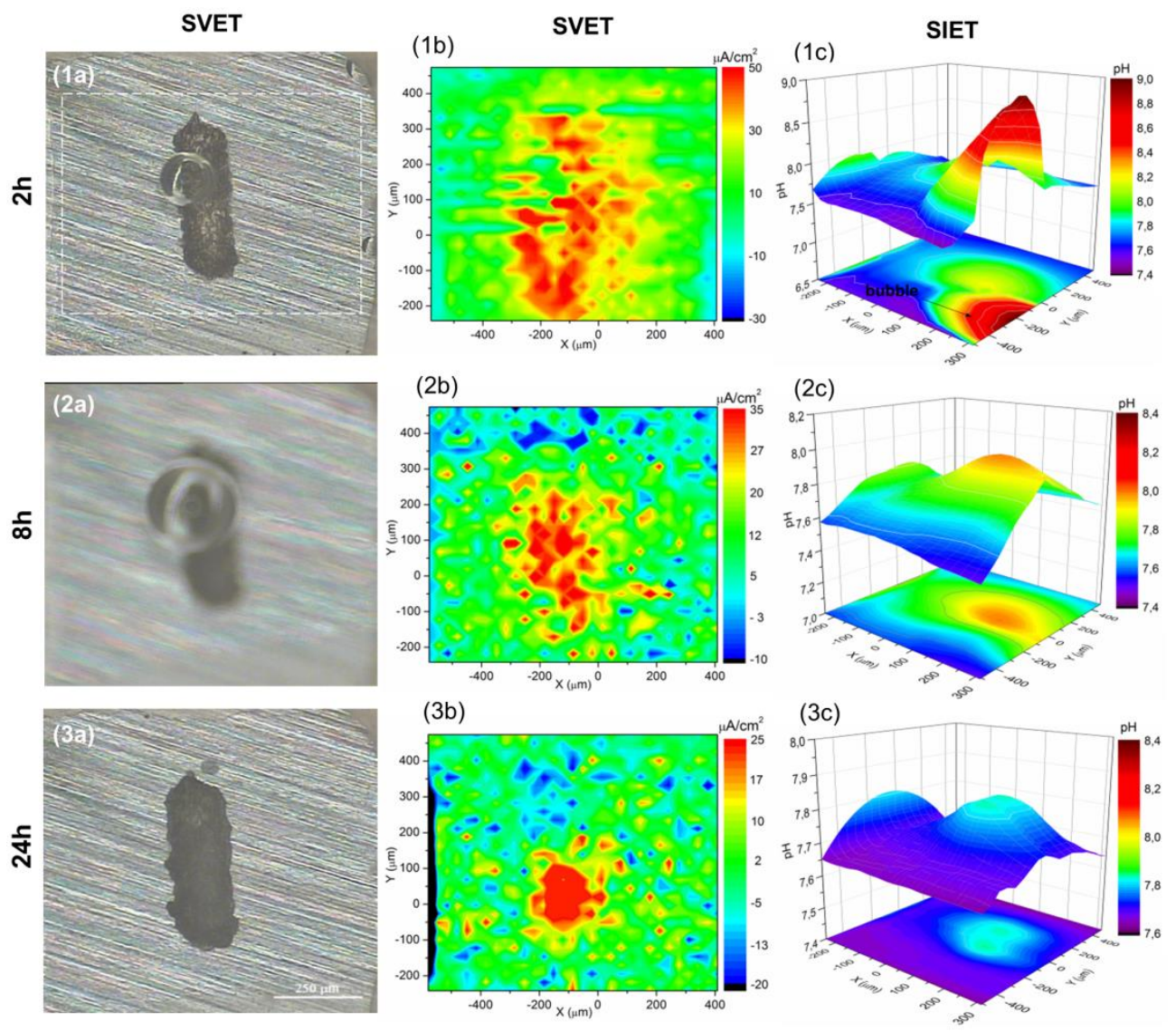

Fig. 7 


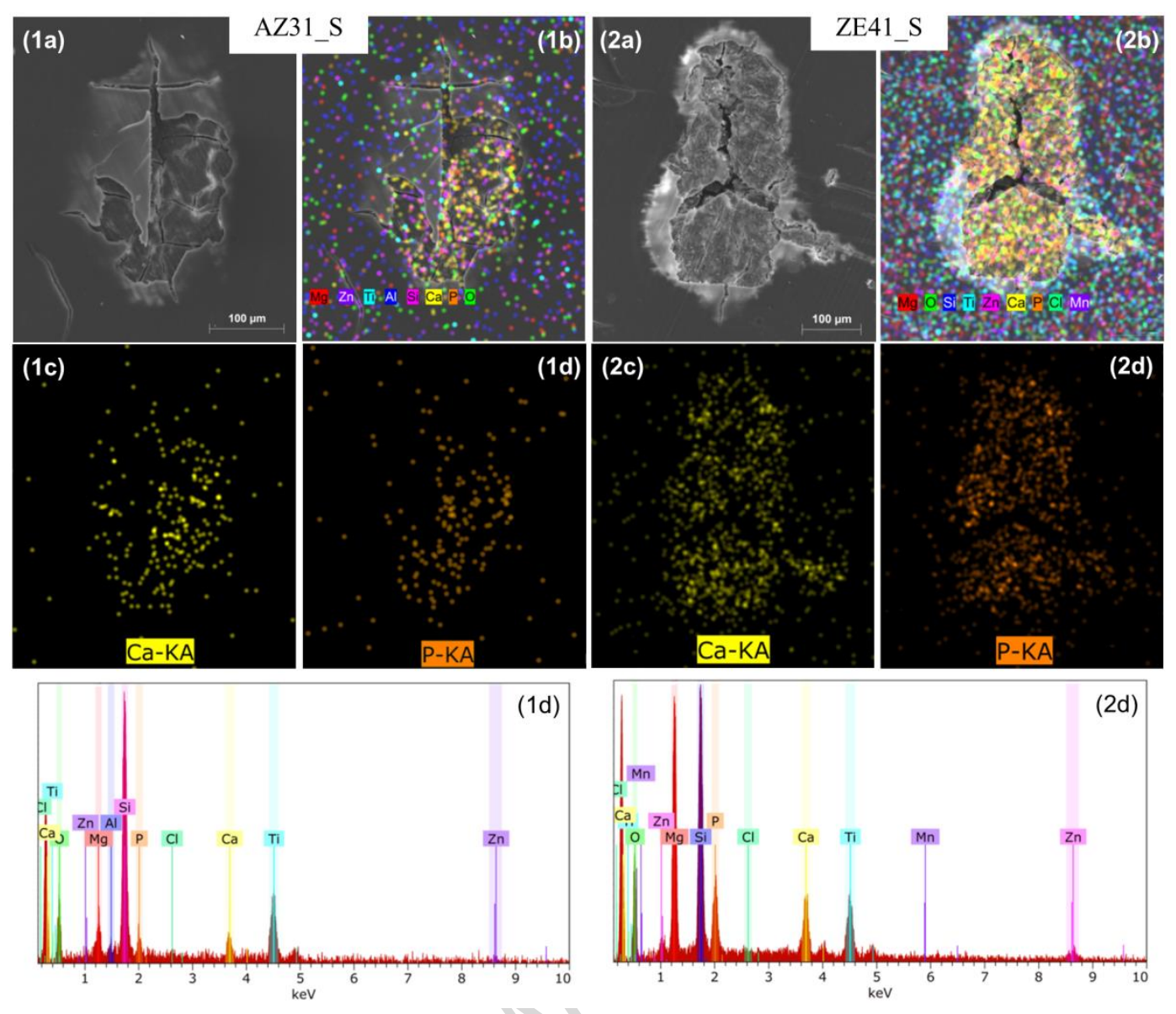

Fig. 8 


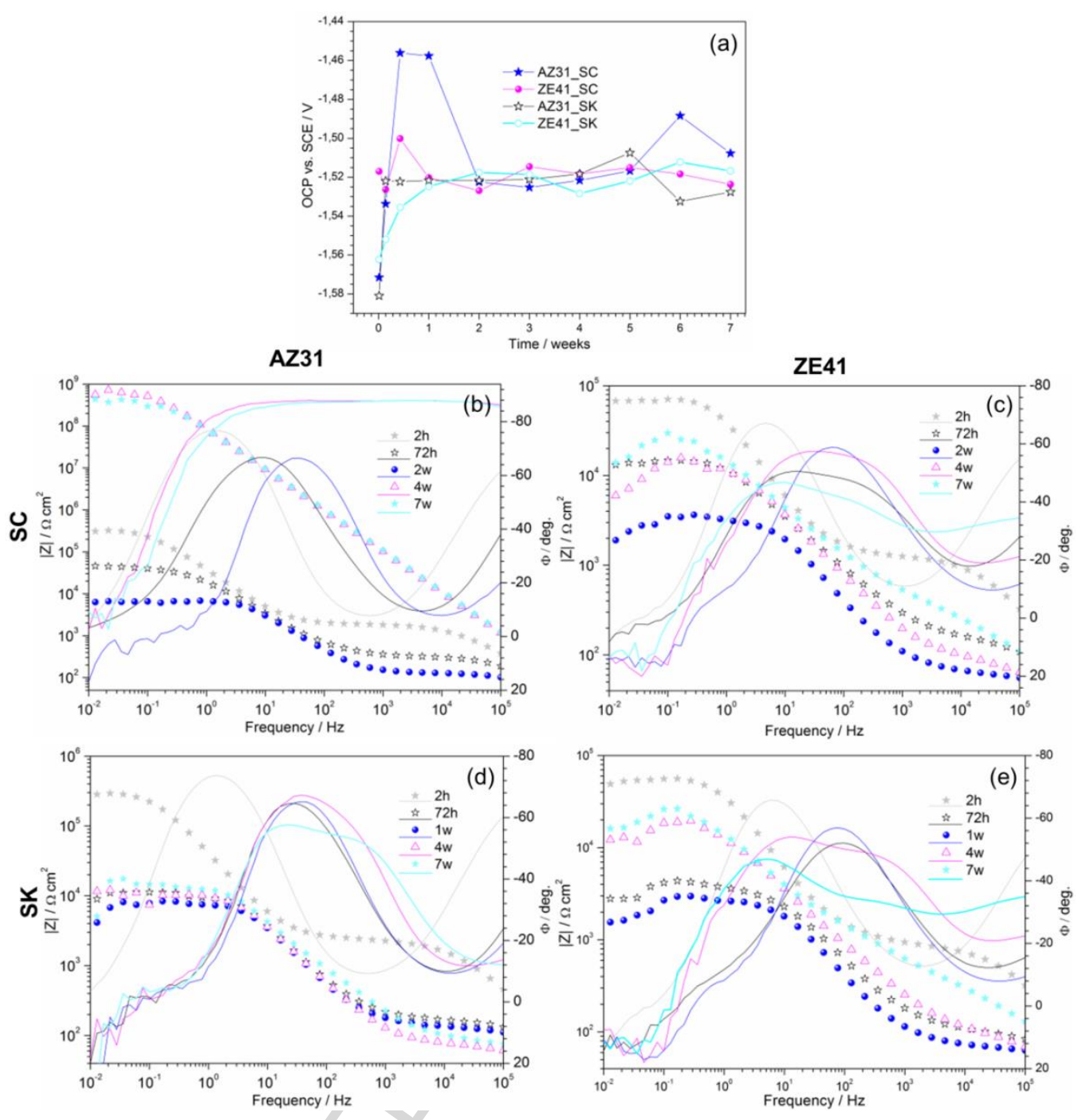

Fig. 9 


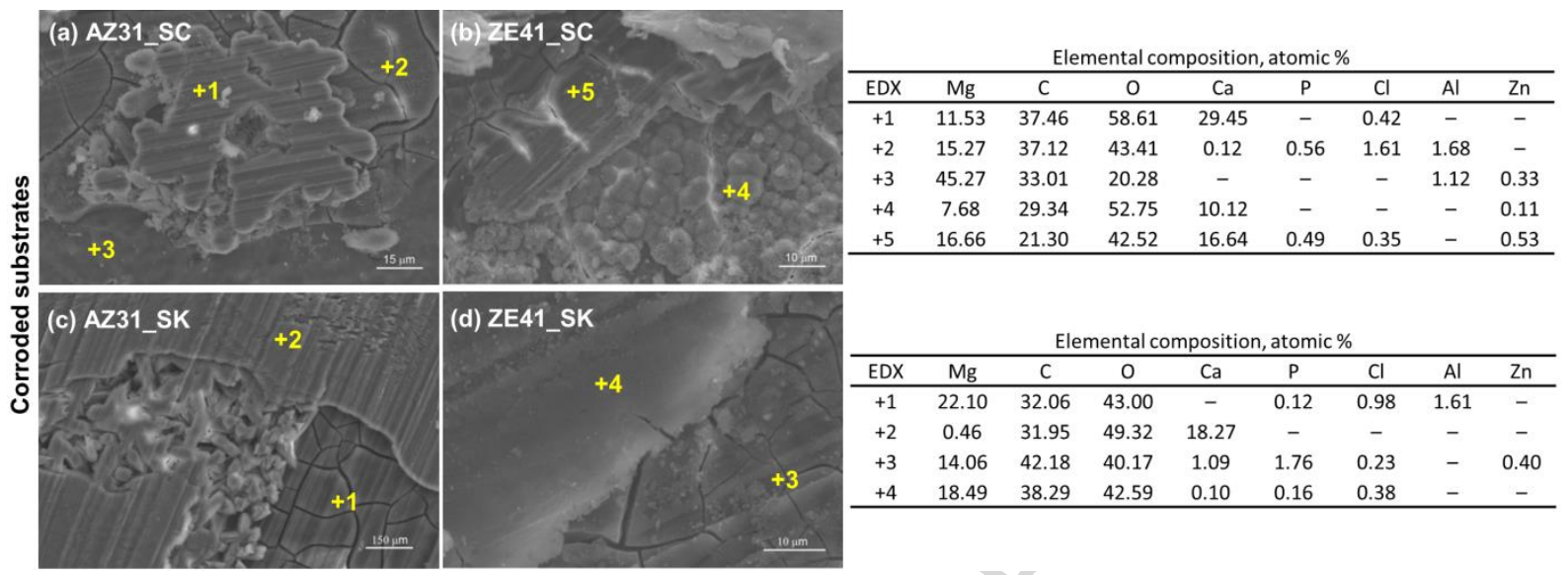

Fig. 10 


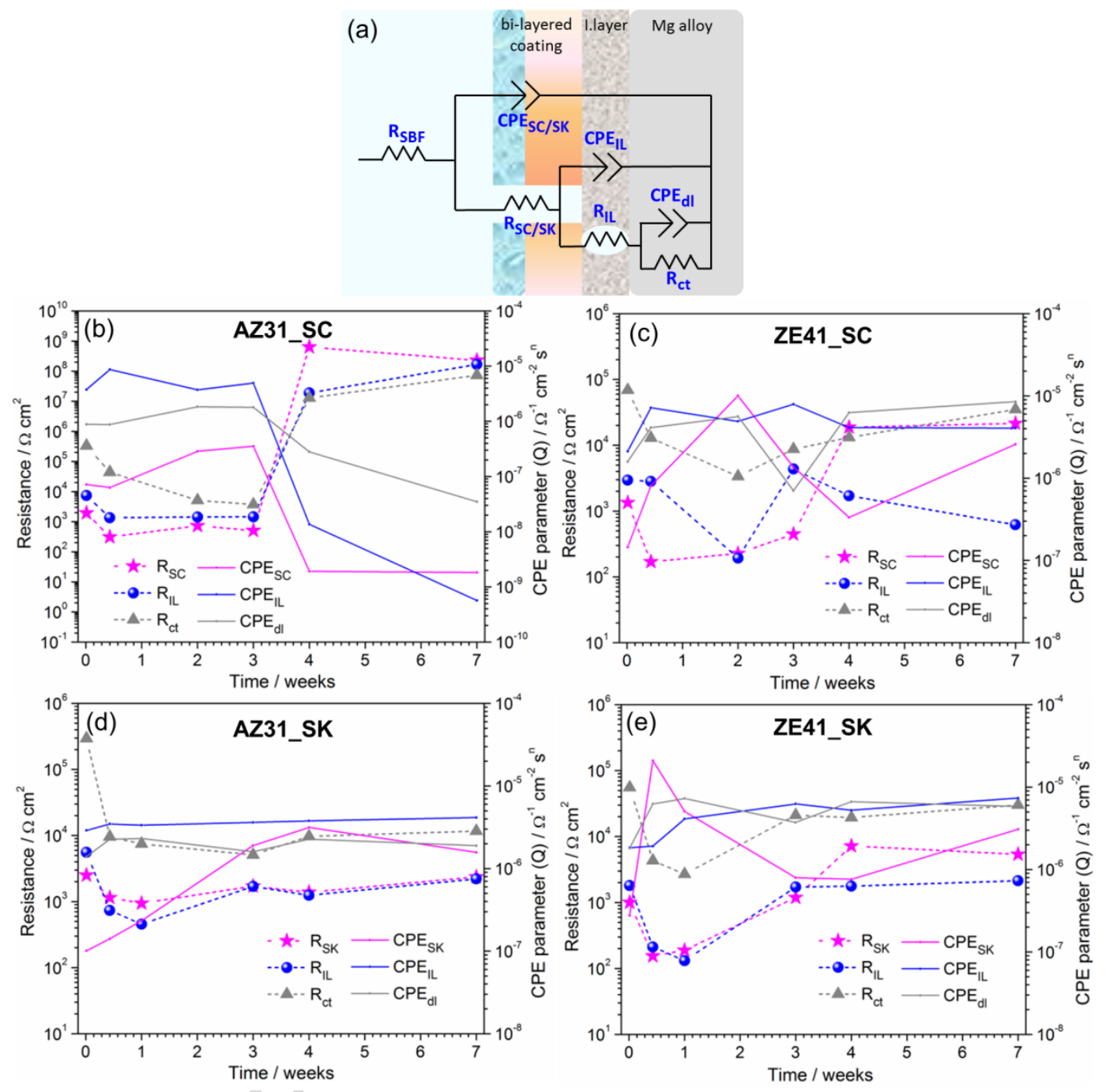

Fig. 11 


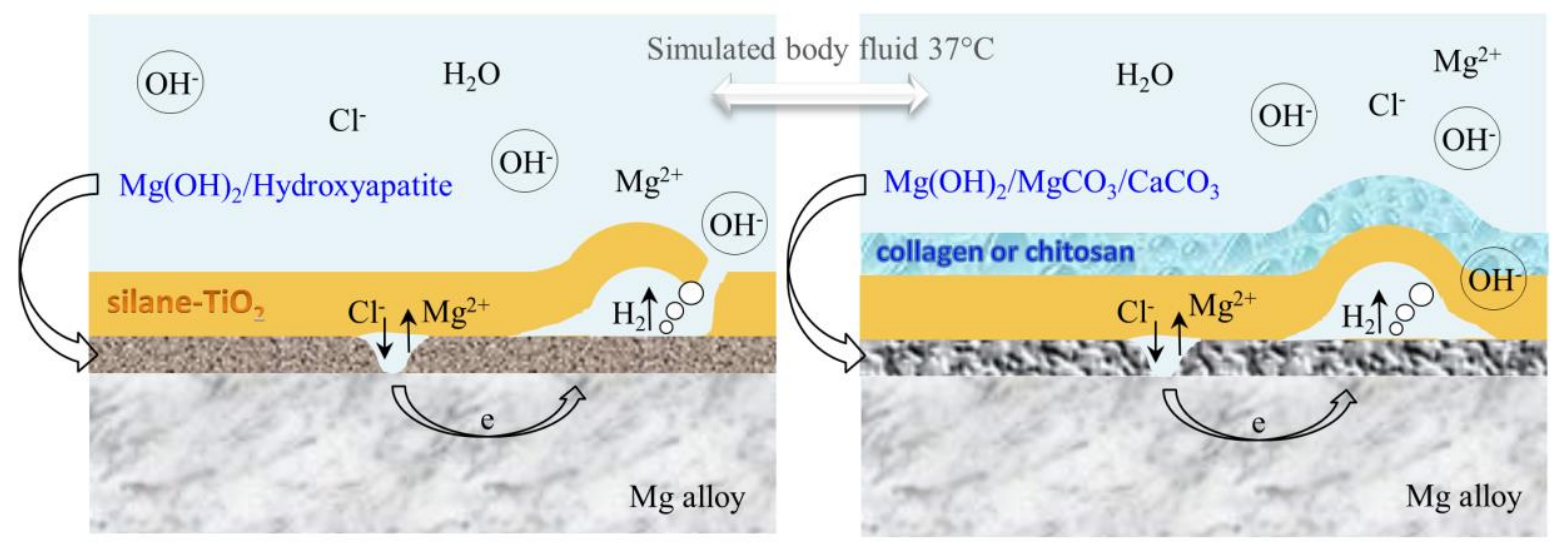

\section{Graphical abstract}




\section{Highlights}

○ Bi-layered sol-gel/biopolymer coatings improved biostability of Mg alloys.

$\circ$ Collagen and chitosan layers trap evolved $\mathrm{H}_{2}$ forming gas pockets.

- Biopolymers promote formation of carbonated compounds into the corrosion products.

- Carbonated phases protect the alloys from further corrosion.

- Long term corrosion mechanisms in biologically-relevant conditions are elucidated. 